\title{
Periostin normalizes levels of cardiac markers in rats with experimental isoproterenol cardiotoxicity
}

\author{
Devrim $\mathrm{AK}^{1}$, Sozmen $\mathrm{M}^{2}$, Devrim $\mathrm{T}^{3}$, Sudagidan $\mathrm{M}^{4}$, Cinar $\mathrm{M}^{1}$, Kabak $\mathrm{YB}^{2}$ \\ Kirikkale University, Faculty of Veterinary Medicine, Department of Biochemistry, Kirikkale, Turkey. \\ tubadevrim@gmail.com
}

\begin{abstract}
BACKGROUND: Although the molecular mechanism of cardiac healing is not fully understood, myocardial infarction is one of the most usual diagnoses in hospitalized patients in industrialized nations while periostin has been recently suggested to have a potential in tissue repairing following myocardial ischemia.

OBJECTIVES: To investigate the effects of periostin on the levels of selected cardiac parameters (cardiac troponin I and T, creatine kinase and creatine kinase isoenzyme-MB), antioxidant/lipid peroxidation parameters (superoxide dismutase, catalase, and malondialdehyde), hepatic parameters (alkaline phosphatase, lactate dehydrogenase, aspartate and alanine transaminases) as well as lipids (total cholesterol, triglyceride, high, low and very-low-density lipoproteins) in a rat model of isoproterenol-induced myocardial injury.

METHODS: A total of 84 male rats were grouped into saline (Group I), periostin (Group II), isoproterenol (Group III) and isoproterenol+periostin (Group IV) groups $(n=21)$. Isoproterenol $(85 \mathrm{mg} / \mathrm{kg} / \mathrm{day})$ and periostin groups were both injected intraperitoneally $(1 \mu \mathrm{g} / \mathrm{kg})$.

RESULTS: Our results revealed that periostin has a positive reducing effect on the levels of analysed parameters especially on cardiac troponins and creatine kinases on days 7 and 28 of the recovery period following the induced experimental heart damage in rats.

CONCLUSION: It is concluded that periostin could have a potential to increase the rate of myocardial recovery after myocardial infarction (Tab. 5, Ref. 28). Text in PDF www.elis.sk.

KEY WORDS: periostin, isoproterenol, acute myocardial infarction, cardiac troponin, creatine kinase.
\end{abstract}

\section{Introduction}

Cardiovascular diseases are the number one cause of death in Europe and much of the world, and more people die annually from cardiovascular diseases than from any other cause. Also, myocardial infarction (MI) is one of the leading causes of death in both men and women $(1,2)$. Previous reports have indicated that during ischemic injury, oxidative stress produced by generation of reactive oxygen species plays an important role in the development of MI $(3,4)$. Several researchers have reported the significant contribution of oxidative stress to the development of cardiovascular diseases, including ischemic injury and MI $(5,6)$.

It has been found that isoproterenol, a synthetic catecholamine, when administered by injection to experimental animals,

${ }^{1}$ Kirikkale University, Faculty of Veterinary Medicine, Department of Biochemistry, Kirikkale, Turkey, ${ }^{2}$ Ondokuz Mayis University, Faculty of Veterinary Medicine, Department of Pathology, Samsun, Turkey, ${ }^{3}$ Kirikkale University, Department of Pathology, Kirikkale, Turkey, and ${ }^{4}$ Konya Food and Agriculture University, SARGEM Laboratories, Konya, Turkey

Address for correspondence: T. Devrim, MD, Department of Pathology, Faculty of Medicine, Kirikkale University, 71450 Kirikkale, Turkey. Phone +90543.2022088, Fax +903183573301

Acknowledgements: This article is a part of the project funded by the Scientific and Technological Research Council of Turkey (TUBITAKTOVAG; Project No.: 114O734). Authors' special thanks are extended to TUBITAK-TOVAG for financial support. induces MI-like necrosis in cardiomyocytes owing to the rise in free radicals, antioxidants and lipid peroxidation and alterations in cardiac enzymes (7). Pathophysiological changes in cardiomyocytes proceeding from the application of isoproterenol in animals have been described as descriptive of those in humans (8) and isoproterenol-induced MI has ordinarily been used as a standard rodent model of MI (9).

Periostin is an extracellular matrix protein and plays a role in cell adhesion, migration, and growth (10). Periostin is expressed in the heart at very early stages of embryogenesis, yet it is not detected in the normal adult myocardium (11). The release of periostin from tissues is increased in situations such as stress and injury (12). Present data emphasizes the regulatory and restorative effects of periostin on various stimuli and stress factors that surround it. However, the biochemical effect of periostin during the ventricular healing process after MI has not yet been studied in detail. We focused on the levels of cardiac antioxidants, lipid peroxidation, and hepatic and lipid parameters to clarify the role of periostin during the cardiac healing period.

\section{Materials and methods}

Eighty-four 6-month old male Sprague-Dawley rats, weighing 210-220 g, were purchased from a private company (Kobay D.H.L. Inc, Ankara, Turkey) and used in the present study. Animals were kept in a temperature-controlled environment $\left(+21 \pm 1^{\circ} \mathrm{C}\right)$ with 
Tab. 1. Details of the experimental design.

\begin{tabular}{|c|c|c|c|c|c|c|c|c|c|c|c|c|c|}
\hline \multirow[t]{2}{*}{ Groups } & \multirow[t]{2}{*}{$\begin{array}{l}\text { Rat } \\
(\mathrm{n})\end{array}$} & \multirow[t]{2}{*}{$\begin{array}{l}\text { Chemical } \\
\text { applied }\end{array}$} & \multirow[t]{2}{*}{ Dosage } & \multicolumn{2}{|c|}{$\begin{array}{c}\text { Isoprotrenol } \\
\text { Application Days }\end{array}$} & \multicolumn{5}{|c|}{$\begin{array}{c}\text { Periostin } \\
\text { Application Days }\end{array}$} & \multicolumn{3}{|c|}{$\begin{array}{l}\text { Sampling Days } \\
\text { Rat (n) }\end{array}$} \\
\hline & & & & 0 & 1 & 1 & 3 & 7 & 14 & 21 & 1 & 7 & 28 \\
\hline 1 & 21 & $\mathrm{~S}$ & $1 \mathrm{ml} / \mathrm{kg}$-IP & $\mathrm{S}$ & $\mathrm{S}$ & S & $\mathrm{S}$ & $\mathrm{S}$ & $\mathrm{S}$ & $\mathrm{S}$ & 7 & 7 & 7 \\
\hline 2 & 21 & $P$ & $1 \mu \mathrm{g} / \mathrm{kg}-\mathrm{IP}$ & - & - & $P$ & $P$ & $P$ & $P$ & $P$ & 7 & 7 & 7 \\
\hline 3 & 21 & $\mathrm{I}$ & $85 \mathrm{mg} / \mathrm{kg}$-IP & I & I & - & - & - & - & - & 7 & 7 & 7 \\
\hline 4 & 21 & $\mathrm{I}+\mathrm{P}$ & $85 \mathrm{mg} / \mathrm{kg}+1 \mu \mathrm{g} / \mathrm{kg}-\mathrm{IP}$ & I & I & $P$ & $P$ & $P$ & $P$ & $P$ & 7 & 7 & 7 \\
\hline
\end{tabular}

$\mathrm{S}$ - saline; $\mathrm{P}$ - periostin; I - isoprotrenol; IP - intraperitoneal application

an alternating 12/12-h light/dark cycle and relative humidity of 50 $\pm 5 \%$, and fed with standard rat chow and water ad libitum. The experimental design and procedures were approved by the Institutional Ethical Committee for Animal Care and Use at the Mehmet Akif Ersoy University, Burdur, Turkey (File no: 93773921-27).

The experiment was performed on 4 groups, each containing 21 rats. Saline was applied subcutaneously $(1 \mathrm{ml} / \mathrm{kg})$ two times in 24-hour intervals to the rats in control group (Group 1). Recombinant periostin peptide $(1 \mu \mathrm{g} / \mathrm{kg})$ dissolved in saline was applied intraperitoneally to group 2 on days 1, 3, 7, 14 and 21, i.e. on the same dates as in group 4. Isoproterenol (Sigma-Aldrich, St. Louis, Missouri, USA, Product code: I6504, $85 \mathrm{mg} / \mathrm{kg} /$ day) dissolved in saline was applied intraperitoneally two times in 24-hour intervals to groups 3 and 4 . Rats in group 4 further received recombinant periostin peptide (Biovision, Milpitas, California USA, Product code; $4205 ; 1 \mu \mathrm{g} / \mathrm{kg}$ ) dissolved in saline intraperitoneally, starting one day after the final isoproterenol administration on days 1 , 3, 7, 14 and 21. Following the final application of periostin, the rats continued to feed routinely with pelleted chow and water ad libitum for further seven days. At the end of days 1, 7 and 28, the rats $(n=7)$ were weighed and sacrificed by cervical dislocation, and blood samples were taken from the tail vein. Experimental setup details are given at Table 1 .

Blood samples used for analyses were transferred to serum tubes, and sera were separated by centrifugation at $2,500 \mathrm{~g}$ for 15 minutes in a refrigerated centrifuge (Hettich) at $+4{ }^{\circ} \mathrm{C}$. Activities of creatine kinase (CK), creatine kinase-MB (CK-MB), lactate dehydrogenase (LDH), aspartate transaminase (AST), alanine transaminase (ALT) and alkaline phosphatase (ALP) were determined spectrophotometrically by use of an auto-analyzer instrument (Chem 200 Chemistry) performing at least 2 measurements as described in the kit.

Serum cTnI and cTnT levels were determined using ELISA kits (Elabscience). The methods recommended by the kits specific to rats were followed, and at least 2 parallel measurements were performed in the microplate reader spectrophotometer (SEAC Sirio S).

The heart tissue and serum samples were examined for the levels of superoxide dismutase (SOD), catalase (CAT) and malondi- aldehyde (MDA), by using a kit (Cayman) and spectrophotometer (SEAC Sirio S). Nitric oxide (NO) concentrations were measured according to the method of Cortas and Wakid (1990) in heart and serum samples (13). Also, total antioxidant (TAS) and total oxidant (TOS) levels were measured in heart and serum samples using commercial assays (Rel Assay Diagnostics).

Analyses of serum total cholesterol (TC), triglyceride (TG), high-density lipoprotein cholesterol (HDL-C) and low-density lipoprotein cholesterol (LDL-C) were conducted using commercial kits (Gesan) and spectrophotometer (Chem 200 Chemistry). Very-low-density lipoprotein cholesterol (VLDL-C) levels were determined according to the Friedewald formula (14).

In the present study, statistical package program (Minitab-12.1) was used for statistical analysis of the data. The obtained values were expressed as mean \pm standard error (mean $\pm \mathrm{SE}$ ). Differences between groups were determined by one-way analysis of variance (ANOVA). The difference of groups was presented by Duncan's test $(\mathrm{p}<0.05)$.

\section{Results}

On all sampling days (days 1, 7 and 28), the groups of isoproterenol-induced cardiotoxicity (groups 3 and 4) showed significant increases in CK and CK-MB enzymes, compared to the controls (groups 1 and 2). Cardiac troponins were decreased significantly $(\mathrm{p}<0.05)$ in the treatment group (group 4) on day 28 (Tab. 2).

There were significant decreases $(p<0.05)$ in the serum and tissue TAS levels of isoproterenol-induced cardiotoxicity groups (groups 3 and 4) on the first day of sampling, compared to the controls (group 1). Also, tissue MDA levels were increased in isoproterenol cardiotoxicity group (group 3) compared to all groups on day 7. Tissue CAT levels were decreased significantly on the first day of isoproterenol-induced cardiotoxicity groups (groups 3 and 4; $<$ 0.05). Tissue and serum SOD levels were increased in isoproterenol-induced cardiotoxicity groups (groups 3 and 4) compared to the controls (group 1) on day 7 (Tab. 3).

Tab. 2. Serum levels of cardiac parameters in the study groups.

\begin{tabular}{|c|c|c|c|c|c|c|c|c|c|c|c|c|}
\hline \multirow{2}{*}{ Parameters } & \multicolumn{4}{|c|}{ DAY 1} & \multicolumn{4}{|c|}{ DAY 7} & \multicolumn{4}{|c|}{ DAY 28} \\
\hline & Group 1 & Group 2 & Group 3 & Group 4 & Group 1 & Group 2 & Group 3 & Group 4 & Group 1 & Group 2 & Group 3 & Group 4 \\
\hline $\mathrm{CK}(\mathrm{U} / \mathrm{l})$ & $118.1 \pm 12.8^{\mathrm{b}}$ & $100 \pm 9.8^{\mathrm{b}}$ & $221 \pm 12^{\mathrm{ab}}$ & $303 \pm 87.5^{\mathrm{a}}$ & $125 \pm 13.6^{\mathrm{b}}$ & $115 \pm 12.3^{b}$ & $363 \pm 42.2^{\mathrm{a}}$ & $278 \pm 44.81^{\mathrm{a}}$ & $118 \pm 15.1^{\mathrm{b}}$ & $117 \pm 15.1^{\mathrm{b}}$ & $338 \pm 84.8^{\mathrm{a}}$ & $263 \pm 21.0^{\mathrm{ab}}$ \\
\hline CK-MB (U/l) & $100.0 \pm 15.7^{\mathrm{b}}$ & $99.4 \pm 10^{\mathrm{b}}$ & $222.8 \pm 11^{\mathrm{a}}$ & $273.5 \pm 49^{\mathrm{a}}$ & $115.5 \pm 10^{\mathrm{c}}$ & $111.2 \pm 6.2^{\mathrm{c}}$ & $342.3 \pm 47^{\mathrm{a}}$ & $250.2 \pm 27^{\mathrm{b}}$ & $116 \pm 12.5^{\mathrm{b}}$ & $87.2 \pm 7.59^{\mathrm{b}}$ & $343.3 \pm 81^{\mathrm{a}}$ & $234.2 \pm 21^{\mathrm{ab}}$ \\
\hline $\mathrm{cTnI}(\mathrm{U} / \mathrm{l})$ & $122.60 \pm 5.64$ & $125.49 \pm 12.5$ & $138.18 \pm 9.31$ & $153.69 \pm 9.94$ & $132.70 \pm 3.63^{\mathrm{ab}}$ & $124.19 \pm 7.1^{\mathrm{bc}}$ & $146.08 \pm 6.75^{\mathrm{a}}$ & $112.54 \pm 2.85^{\mathrm{c}}$ & $125.58 \pm 5.45^{\mathrm{ab}}$ & $129.81 \pm 6.16^{\mathrm{ab}}$ & $150.02 \pm 11.7^{\mathrm{a}}$ & $115.98 \pm 5.61^{\mathrm{b}}$ \\
\hline $\mathrm{cTnT}(\mathrm{U} / \mathrm{l})$ & $65.12 \pm 2.17^{\mathrm{bc}}$ & $63.44 \pm 5.6^{c}$ & $74.36 \pm 1.95^{\mathrm{b}}$ & $106.51 \pm 2.76^{\mathrm{a}}$ & $65.52 \pm 4.11^{\mathrm{b}}$ & $63.36 \pm 3.66^{\mathrm{b}}$ & $89.47 \pm 8.52^{\mathrm{ab}}$ & $108.71 \pm 11.98^{\mathrm{a}}$ & $74.19 \pm 2.91^{\mathrm{b}}$ & $67.69 \pm 3.91^{\mathrm{b}}$ & $94.68 \pm 4.32^{\mathrm{a}}$ & $75.07 \pm 7.94^{b}$ \\
\hline
\end{tabular}




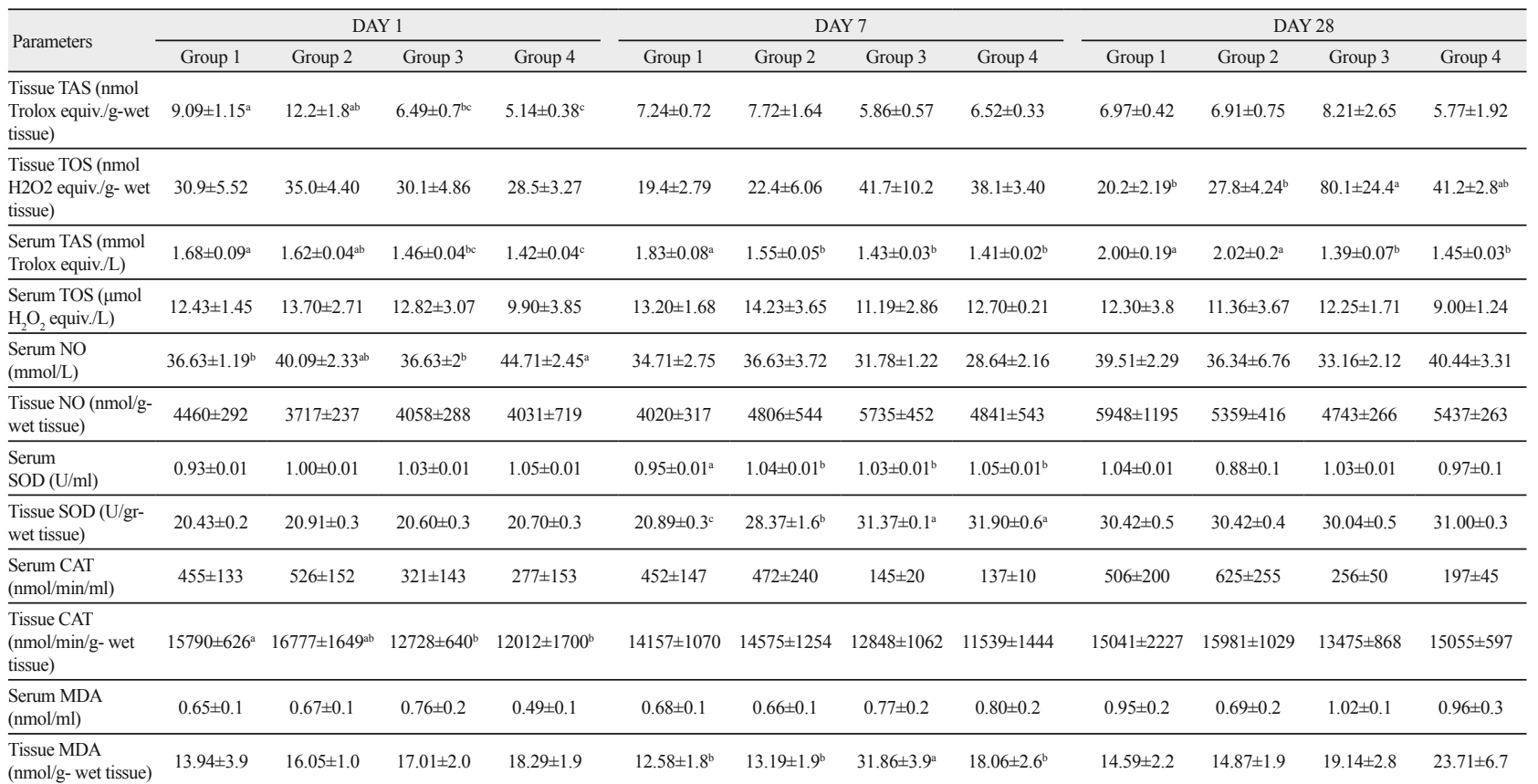

TAS - total antioxidant status, TOS - total oxidant status, NO - nitric oxide, SOD - superoxide dismutase, CAT - catalase, MDA - malondialdehyde, mean value \pm standard error. The different letters on the same days $(\mathrm{a}, \mathrm{b}, \mathrm{c})$ show statistical differences $(\mathrm{p}<0.05)$ between the groups.

Tab. 4. Levels of serum hepatic parameters in the study groups.

\begin{tabular}{|c|c|c|c|c|c|c|c|c|c|c|c|c|}
\hline \multirow{2}{*}{ Parameters } & \multicolumn{4}{|c|}{ DAY 1} & \multicolumn{4}{|c|}{ DAY 7} & \multicolumn{4}{|c|}{ DAY 28} \\
\hline & Group 1 & Group 2 & Group 3 & Group 4 & Group 1 & Group 2 & Group 3 & Group 4 & Group 1 & Group 2 & Group 3 & Group 4 \\
\hline AST (U/1) & $111.6 \pm 2.04$ & $110.6 \pm 1.96$ & $116.0 \pm 4.74$ & $115.6 \pm 8.24$ & $106.5 \pm 1.69$ & $103.4 \pm 1.87$ & $117.1 \pm 8.23$ & $111.5 \pm 4.26$ & $104.5 \pm 3.8^{b}$ & $113.4 \pm 4.3^{\mathrm{b}}$ & $123.9 \pm 3.4^{\mathrm{a}}$ & $107,3 \pm 2,2^{\mathrm{b}}$ \\
\hline $\operatorname{ALT}(\mathrm{U} / \mathrm{l})$ & $39.7 \pm 1.84^{b}$ & $36.4 \pm 2.77^{b}$ & $58.3 \pm 2.87^{\mathrm{a}}$ & $55.6 \pm 9.06^{\mathrm{a}}$ & $43.14 \pm 3.51$ & $42.29 \pm 3.37$ & $46.22 \pm 1.78$ & $44.33 \pm 2.36$ & $41.14 \pm 1.5$ & $46.29 \pm 1.89$ & $45.00 \pm 1.4$ & $46,27 \pm 0,85$ \\
\hline $\operatorname{ALP}(\mathrm{U} / \mathrm{l})$ & $313 \pm 21.2^{b}$ & $288 \pm 15.7^{b}$ & $500.5 \pm 15.8^{\mathrm{a}}$ & $443 \pm 42.5^{\mathrm{a}}$ & $403.7 \pm 41.4$ & $429.5 \pm 29.7$ & $452.3 \pm 14.3$ & $487.1 \pm 18.3$ & $397 \pm 10.8^{b}$ & $403 \pm 29.6^{b}$ & $474 \pm 15.9^{\mathrm{a}}$ & $474 \pm 18,5^{\mathrm{a}}$ \\
\hline$\overline{\mathrm{LDH}}(\mathrm{U} / \mathrm{l})$ & $958.5 \pm 54.6^{b}$ & $1089 \pm 94^{b}$ & $1480 \pm 162^{a}$ & $1582 \pm 81^{\mathrm{a}}$ & $1179 \pm 132$ & $1201 \pm 142$ & $1441 \pm 115$ & $1380 \pm 111$ & $1108 \pm 157$ & $1207 \pm 150$ & $1256 \pm 54$ & $1246 \pm 96$ \\
\hline
\end{tabular}

AST - aspartate transaminase, ALT - alanine transaminase, ALP - alkaline phosphatase, LDH - lactate dehydrogenase, mean value \pm standard error. The different letters on the same days (a, b, c) show statistical differences $(\mathrm{p}<0.05)$ between the groups.

Tab. 5. Levels of serum lipids in the study groups.

\begin{tabular}{|c|c|c|c|c|c|c|c|c|c|c|c|c|}
\hline \multirow{2}{*}{ Parameters } & \multicolumn{4}{|c|}{ DAY 1} & \multicolumn{4}{|c|}{ DAY 7} & \multicolumn{4}{|c|}{ DAY 28} \\
\hline & Group 1 & Group 2 & Group 3 & Group 4 & Group 1 & Group 2 & Group 3 & Group 4 & Group 1 & Group 2 & Group 3 & Grup 4 \\
\hline $\mathrm{TC}(\mathrm{mg} / \mathrm{dl})$ & $52.57 \pm 1.82$ & $46.0 \pm 4.57$ & $56.17 \pm 2.04$ & $56.17 \pm 4.25$ & $45.5 \pm 1.23^{b}$ & $43.1 \pm 2.74^{\mathrm{b}}$ & $45.0 \pm 1.58^{\mathrm{b}}$ & $55.5 \pm 1.66^{\mathrm{a}}$ & $48.5 \pm 2.80$ & $52.0 \pm 2.10$ & $48.4 \pm 1.46$ & $54,1 \pm 1,85$ \\
\hline $\mathrm{TG}(\mathrm{mg} / \mathrm{dl})$ & $37.00 \pm 6.33$ & $33.0 \pm 4.31$ & $40.83 \pm 3.36$ & $48.83 \pm 4.75$ & $58.71 \pm 5.8$ & $55.43 \pm 2.21$ & $60.11 \pm 2.2$ & $63.56 \pm 4.71$ & $54.86 \pm 7.5$ & $52.57 \pm 5.78$ & $55.64 \pm 4.64$ & $61,09 \pm 6,31$ \\
\hline LDL (mg/dl) & $17.14 \pm 0.96$ & $14.2 \pm 1.42$ & $14.17 \pm 1.1$ & $17.17 \pm 1.83$ & $13.4 \pm 0.36^{b}$ & $12.7 \pm 1.28^{b}$ & $10.2 \pm 0.77^{\mathrm{c}}$ & $16.1 \pm 0.77^{\mathrm{a}}$ & $16.43 \pm 0.64$ & $16.57 \pm 0.84$ & $15.82 \pm 0.91$ & $15,73 \pm 0,61$ \\
\hline HDL (mg/dl) & $32.57 \pm 1.39$ & $27.4 \pm 2.75$ & $28.83 \pm 2.15$ & $34.00 \pm 2.86$ & $26.8 \pm 0.59^{b}$ & $27.0 \pm 1.66^{\mathrm{b}}$ & $25.4 \pm 0.83^{b}$ & $32.8 \pm 1.27^{\mathrm{a}}$ & $29.0 \pm 1.5^{\mathrm{ab}}$ & $30.1 \pm 0.73^{\mathrm{a}}$ & $26.4 \pm 1.06^{\mathrm{b}}$ & $30,82 \pm 0,95^{\mathrm{a}}$ \\
\hline VLDL-C (mg/dl) & $7.40 \pm 1.26$ & $6.60 \pm 0.86$ & $8.17 \pm 0.67$ & $9.77 \pm 0.95$ & $11.74 \pm 1.16$ & $11.09 \pm 0.44$ & $12.02 \pm 0.44$ & $12.71 \pm 0.94$ & $10.97 \pm 1.5$ & $10.51 \pm 1.15$ & $11.13 \pm 092$ & $12,22 \pm 1,26$ \\
\hline
\end{tabular}

TC - total cholesterol, TG - triglyceride, LDL-C - low density lipoprotein-cholesterol, HDL-C - high density lipoprotein-cholesterol, VLDL-C - very low density lipoprotein-cholesterol, mean value \pm standard error. The different letters on the same days $(a, b, c)$ show statistical differences $(\mathrm{p}<0.05)$ between the groups.

On the first day in the groups of isoproterenol-induced cardiotoxicity (groups 3 and 4), there were significant increases in ALT, ALP, and LDH $(p<0.05)$ compared to the controls (groups 1 and 2 ). The same result of increased ALP levels was repeated on day 28 of sampling (Tab. 4). Also, there were interesting increases in LDL, HDL, and TC in the treatment group (group 4) on day 7 of sampling (Tab. 5).

\section{Discussion}

The therapeutic roles of different administrations against isoproterenol-induced myocardial injury have been discussed previ- ously. Nivethetha et al (2009) investigated the protective effect of M. calabra plant extract in a rat model and reported an increase in serum AST values in the isoproterenol group compared to the control group on days 29-30 (15). Afroz et al (2016) reported increased serum ALT values in MI and MI+treatment groups in rats with isoproterenol-induced myocardial injury 24 hours after the last isoproterenol administration (16). In a study examining the effect of Urtica parviflora roxb. extract, Barman et al (2013) reported increased LDH, AST, ALT and ALP activities in the sera of $\mathrm{MI}$ and treatment groups in isoproterenol-injected rats (17). These results are consistent with our study, indicating that isoproterenol administration induces AST, ALT and LDH levels possibly due 
to the rise in the activities of the innervated lysosomal enzymes . Although, ALT, ALP and LDH values were high in both, treated and non-treated cardiotoxicity groups, periostin provided a normalizing AST level on day 28 in the treatment group, presumably caused by the hepatoprotective potential during long-term administration.

As in the present study, significant increases in serum CK and CK-MB enzymes were also reported in other studies in isoproterenol-treated rats $(18,19)$. On the other hand, in the present study's treatment group (group 3), periostin was found to positively affect $\mathrm{CK}$ and CK-MB enzyme activities, probably by contributing to the structural and functional integrity of cellular membranes in cardiomyocytes.

Prabhu et al (2006) reported the protective effect of magniferin on days 7, 14, 28 and 35 of isoproterenol-induced myocardial injury in rats and determined serum CK increase in all sampling days as observed in the present study. They reported a dose-dependent CK decrease in the magniferin treatment groups on day 28 (20). Similar CK decrease also occurred in the present study, probably caused by the cardioprotective potential of periostin which developed during 4 weeks of administration.

Patel et al (2010) examined the cardioprotective effects of melatonin on isoproterenol-induced MI in rats. The researchers reported that CK-MB levels were increased in MI and treatment groups on day 7 of melatonin administration, and these increases were significantly normalized in the treatment group compared to the MI group (21). When the values of CK-MB obtained in our study are evaluated together with the data in the literature, it was seen that there was a significant decrease in the treatment group on day 7 in comparison to MI group, and this was probably due to the result of the cardioprotective effect of periostin.

$\mathrm{CTnI}$ and cTnT are commonly used markers for early detection of heart damage. There is a close correlation between the severity of morphological damage and serum levels of cTnI and cTnT as from the onset of myocardial degeneration and necrosis. In a study by York et al (2007), changes of serum cTnI and cTnT levels during time intervals in isoproterenol-treated rats were reported (22). Researchers declared that both parameters began to exceed the control group value one hour after the isoproterenol administration and started to fall after reaching the peak value at the second hour. In addition, investigators reported that $\mathrm{cTnI}$ levels returned to normal in the first 24 hours. As for the present study, although not statistically supported, cTnI levels on the first sampling day were obtained as high mean values in isoproterenol-treated heart failure and treatment groups (groups 3 and 4), and it was consistent with the finding of York et al (2007). On other days (days 7 and 28), there was a significant decrease in the levels of cTnI in the treatment groups which could be due to the positive effect of periostin on the MI group.

Serum cTnT levels of the first day showed significant increases in the MI groups (groups 3 and 4) compared to the recombinant periostin control group (group 2). This result was consistent with the assertion of York et al (2007), suggesting the return of cTnT levels to normal after 48 hours of isoproterenol administration (22). In the present study, the levels of the treatment group (group 4) decreased and reached to the levels of the controls (groups 1 and 2) on day 28 and it is thought to be the result of a positive effect of periostin on myocardial regeneration. Additionally, it was evaluated that in comparison to the isoproterenol group, lower serum levels of cTnI and cTnT in the isoproterenol+periostin group could support the cardioprotective effects of periostin.

The level of HDL-C was significantly increased in the isoproterenol+periostin group (group 3) compared to the isoproterenol group (group 4). This is important because periostin possibly affects the lipid profile positively.

Serum SOD levels of the study groups did not differ on days 1 and 28, but on day 7 there was a slight increase in the other groups in comparison with the controls (group 1). Similar findings were also observed in tissue SOD levels. There were no differences between days 1 and 28 in control groups, but there were increases in the MI groups (groups 3 and 4) on day 7, compared to the controls (groups 1 and 2). Oktar et al (2010) investigated the effects of caffeic acid phenethyl ester on isoproterenol-induced MI $(150 \mathrm{mg} / \mathrm{kg}, \mathrm{SC})$ in rats and 48 hours after the last isoproterenol application they found slight decreases in the treatment and MI groups (23). This reported difference from our study is probably the result of disparities in isoproterenol dose and/or time of euthanasia application.

CAT activity was decreased in the rat heart tissues and sera of isoproterenol and isoproterenol+periostin groups (groups 3 and 4). The differences between groups of tissue CAT levels were similar to those of serum CAT values. On day 1 , significant decreases in MI groups (groups 3 and 4) compared to the control groups (groups 1 and 2) were noted. In an isoproterenol-induced MI $(85 \mathrm{mg} / \mathrm{kg})$ study investigating the cardioprotective potential of myricetin in rats, Tiwari et al (2009) reported significant decreases in the MI group on day 1, compared to the control groups (24). This reported finding is consistent with our study. Tissue MDA levels were significantly increased on day 7 in the isoproterenol-treated group (group 3). Goyal et al (2015) induced heart damage in rats by isoproterenol $(85 \mathrm{mg} / \mathrm{kg})$ and reported similar high MDA levels in heart-damaged groups, which is consistent with our study (25).

In their study of isoproterenol-induced heart damage, Chagoya de Sánchez et al (2012) investigated NO levels in euthanized rats $0.5,1,3,6,12,24,48,72$ and 96 hours after isoproterenol administration and found an increase in the treatment (nitro-L-arginine methyl ester) group as compared to the acute MI group in agreement with our findings (26).

In consistency with literature $(27,28)$, decreased TAS levels were determined in isoproterenol-induced heart damage group (group 3) and for this reason isoproterenol probably could produce the effect of reducing TAS levels in tissue and serum samples. Tissue TOS levels were significantly higher in the MI group (group 3 ) than in the control group (group 1 and 2) on sampling day 28. This finding is consistent with the findings of Kocak et al (2016) who examined the protective effects of embelin and carnosic acid on isoproterenol-induced heart damage in rats (28).

To sum up, our results demonstrated that periostin has a normalizing effect on the levels of analyzed parameters, especially 
cardiac troponins and creatine kinases displayed on days 7 and 28 of the recovery period following the induced experimental heart damage in rats. In the light of the presented data, it is concluded that periostin could have a potential to increase the rate of recovery of myocardial injury after MI.

\section{References}

\section{1. http://www.who.int/mediacentre/factsheets/fs317/en/}

2. Wawruch M, Slezakova V, Murin J, Kuzelova M, Dukat A, Zabka M, Leitmann T, Tisonova J, Kallay Z. The use of antiplatelet medication in hospitalised elderly patients. Bratisl Med J 2015; 116 (9): 533-538.

3. Kucybala I, Janas P, Ciuk S, Cholopiak W, Klimek-Piotrowska W, Holda MK. A comprehensive guide to telocytes and their great potential in cardiovascular system. Bratisl Med J 2017; 118 (5): 302-309.

4. He F, Zuo L. Redox roles of reactive oxygen species in cardiovascular diseases. Int J Mol Sci 2015; 16: 27770-27780.

5. Okafor ON, Farrington K, Gorog DA. Allopurinol as a therapeutic option in cardiovascular disease. Pharmacol Ther 2017; 172: 139-150.

6. Mohammad R. Momordica charantia polysaccharides ameliorate oxidative stress, hyperlipidemia, inflammation, and apoptosis during myocardial infarction by inhibiting the NF-kappa B signaling pathway. Int J Biol Macromol 2017; 97: 544-551.

7. Rathore N, John S, Kale M, Bhatnagar D. Lipid peroxidation and antioxidant enzymes in isoproterenol induced oxidative stress in rat tissues. Pharmacol Res 1998; 38: 297-303.

8. Wexler BC. Myocardial infarction in young vs old male rats: Pathophysiologic changes. Am Heart J 1978; 96 (1): 70-80.

9. Karthikeyan K, Bai BRS, Devaraj SN. Grape seed proanthocyanidins ameliorates isoproterenol-induced myocardial injury in rats by stabilizing mitochondrial and lysosomal enzymes: an in vivo study. Life Sci 2007; 81: 1615-1621.

10. Snider P, Standley KN, Wang J, M Azhar, Doetschman T, Conway SJ. Origin of cardiac fibroblasts and the role of periostin. Circ Res 2009; 105: 934-947.

11. Norris RA, Moreno-Rodriguez R, Hoffman S, Markwald RR. The many facets of the matricelluar protein periostin during cardiac development, remodeling, and pathophysiology. J Cell Commun Signal 2009; 3: $275-286$

12. Rani,S, Barbe MF, Barr AE, Litvin J. Periostin-like-factor and periostin in an animal model of work-related musculoskeletal disorder. Bone 2009; 44: 502-512.

13. Cortas NK, Wakid NW. Determination of inorganic nitrate in serum and urine by a kinetic cadmium-reduction method. Clin Chem 1990; 36 : 1440-1443.
14. Friedewald WT, Levy RI, Fredrickson DS. Estimation of the concentration of low-density lipoprotein cholesterol in plasma, without use of the preparative ultracentrifuge. Clin Chem 1972; 18: 499-502.

15. Nivethetha M, Jayasri J, Brindha P. Effects of Muntingia calabura L. on isoproterenol-induced myocardial infarction. Singapore Med J 2009; 50: $300-302$.

16. Afroz R, Tanvir EM, Karim $\mathbf{N}$ et al. Sundarban honey confers protection against isoproterenol-induced myocardial infarction in wistar rats. Biomed Res Int 2016; Article ID 6437641. doi: 10.1155/2016/6437641.

17. Barman NR, Nandy S, Datta R, Kar PK. Cardioprotective effect of ethanolic extract of Urtica parviflora Roxb. against isoproterenol induced myocardial infarction in rats. Indian J Pharmacol 2013; 45: 513-516.

18. Mair J. Cardiac troponin I and troponin T: are enzymes still relevant as cardiac markers? Clin Chim Acta 1997; 257: 99-115.

19. Kurian GA, Philips S, Varghese T. Effect of aqueous extract of the desmodium gangeticum DC root in the severity of myocardial infarction. J Ethanopharmacol 2005; 97: 457-461.

20. Prabhu S, Jainu M, Sabitha KE, Devi CS. Cardioprotective effect of mangiferin on isoproterenol induced myocardial infarction in rats. Indian J Exp Biol 2006; 44: 209-215.

21. Patel V, Upaganlawar A, Zalawadia R, Balaraman R. Cardioprotective effect of melatonin against isoproterenol induced myocardial infarction in rats: A biochemical, electrocardiographic and histoarchitectural evaluation. Eur J Pharmacol 2010; 10: 160-168.

22. York M, Scudamore C, Brady S et al. Characterization of troponin responses in isoproterenol - induced cardiac injury in the Hanover Wistar rat. Toxicol Pathol 2007; 35: 606-617.

23. Oktar S, Aydin M, Yönden Z, Alçin E, Ilhan S, Nacar A. Effects of caffeic acid phenethyl ester on isoproterenol-induced myocardial infarction in rats. Anatol J Cardiol 2010; 10 (4): 298-302.

24. Tiwari R., Mohan M, Kasture S, Maxia A, Ballero M. Cardioprotective potential of myricetin in isoproterenol-induced myocardial infarction in Wistar rats. Phytother Res 2009; 23: 1361-1366.

25. Goyal SN, Sharma C, Mahajan UB et al. Protective Effects of Cardamom in Isoproterenol-Induced Myocardial Infarction in Rats. Int J Mol Sci 2015; 16 (11): 27457-27469.

26. Chagoya De Sánchez V, Yañez-Maldonado L, Vidrio-Gómez S et al. Role of nitric oxide in isoproterenol-induced myocardial infarction. Cardiotoxicity of Oncologic Treatments. InTech 2012. doi: 10.5772/34505.

27. Salimeh A, Mohammadi M, Mohaddes G, Badalzadeh R. Protective effect of diosgenin and exercise training on biochemical and ecg. alteration in isoproterenol- induced myocardial infarction in rats. Iran J Basic Med Sci 2011; 3: 264-274.

28. Kocak C, Kocak FE, Akcilar R, Isiklar OO, Kocak H, Bayat Z et al. Molecular and biochemical evidence on the protective effects of embelin and carnosic acid in isoproterenol-induced acute myocardial injury in rats. Life Sci 2016; 147: 15-23. 